\title{
The Origins of the Alternating Schwarz Method
}

\author{
Martin J. Gander ${ }^{1}$ and Gerhard Wanner ${ }^{1}$
}

\section{Introduction}

Schwarz methods are nowadays known as parallel solvers, and there are many variants: alternating and parallel Schwarz methods at the continuous level, additive and multiplicative Schwarz methods at the discrete level, also with restricted variants, which in the additive case build the important bridge between discrete and continuous Schwarz methods, see [4]. But where did these methods come from? Why were they invented in the first place? We explain in this paper that Hermann Amandus Schwarz invented the alternating Schwarz method in [18] to close an important gap in the proof of the Riemann mapping theorem, which was based on the Dirichlet principle. The Dirichlet principle itself addresses the important question of existence and uniqueness of solutions of Laplace's equation on a bounded domain with Dirichlet boundary conditions, and in the 19th century, this equation appeared independently in many different areas. It was therefore of fundamental importance to put the Dirichlet principle on firm mathematical grounds, and this is one of the major achievements of Schwarz.

\section{Laplace's equation}

In his Principia in 1687, Newton presented among many results also his famous inverse square law for celestial bodies [15, end of proof of Prop. XI $]^{1}$ :

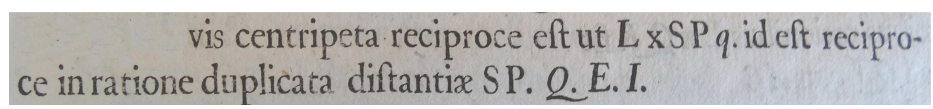

see also [20] for a comprehensive treatment of the influence of Kepler and Newton on numerical analysis. In modern notation, if we denote by $\mathbf{f}$ the force between two celestial bodies, then $\mathbf{f}$ is proportional to $\frac{1}{r^{2}}$, where $r:=\sqrt{(x-\xi)^{2}+(y-\eta)^{2}+(z-\zeta)^{2}}$, using the notation in Figure 1. Writing $\mathbf{f}=\left(f_{1}, f_{2}, f_{3}\right)$ component-wise, we obtain for the components

$$
f_{1} \approx \frac{x-\xi}{r^{3}}, \quad f_{2} \approx \frac{y-\eta}{r^{3}}, \quad f_{1} \approx \frac{z-\zeta}{r^{3}} .
$$

University of Geneva, Section of Mathematics, 2-4 rue du Lièvre, CP 64, CH-1211 Geneva 4, e-mail: \{Martin.Gander, Gerhard.Wanner\}@unige.ch

${ }^{1}$ The centripetal force is inverse to $L \times S P^{2}$, it is inversely proportional to the squared distance $S P$. Q.E.I. 


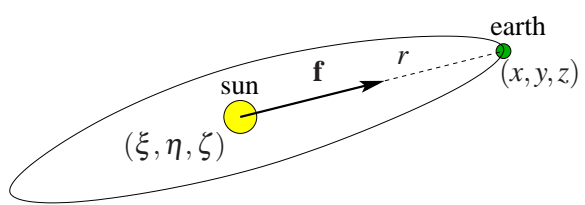

Fig. 1 The sun and our planet earth, for which Newton's inverse square law holds

This very elegant and simple law is at first only valid for point masses. Laplace then, from 1785 onwards, was wondering how these forces look like if the body is not a point, but a three dimensional irregular object occupying a domain $V \subset$ $\mathbb{R}^{3}$. A clear exposition of his ideas only appeared in his Mécanique Céleste from 1799, see [9]. He imagined that the body is composed of molecules, see the original reproduced in Figure 2. In that case, one would need to sum the contributions of all the infinitesimally small body parts ("molecules") making up the entire volume, and would thus obtain for example for the first component of the force

$$
f_{1}=\int_{V} \rho(\xi, \eta, \zeta) \frac{x-\xi}{r^{3}} d \xi d \eta d \zeta
$$

where $\rho$ denotes the density of the body. The key idea of Laplace was now to introduce the potential function

$$
u=\iiint \rho(\xi, \eta, \zeta) \frac{1}{r} d \xi d \eta d \zeta
$$

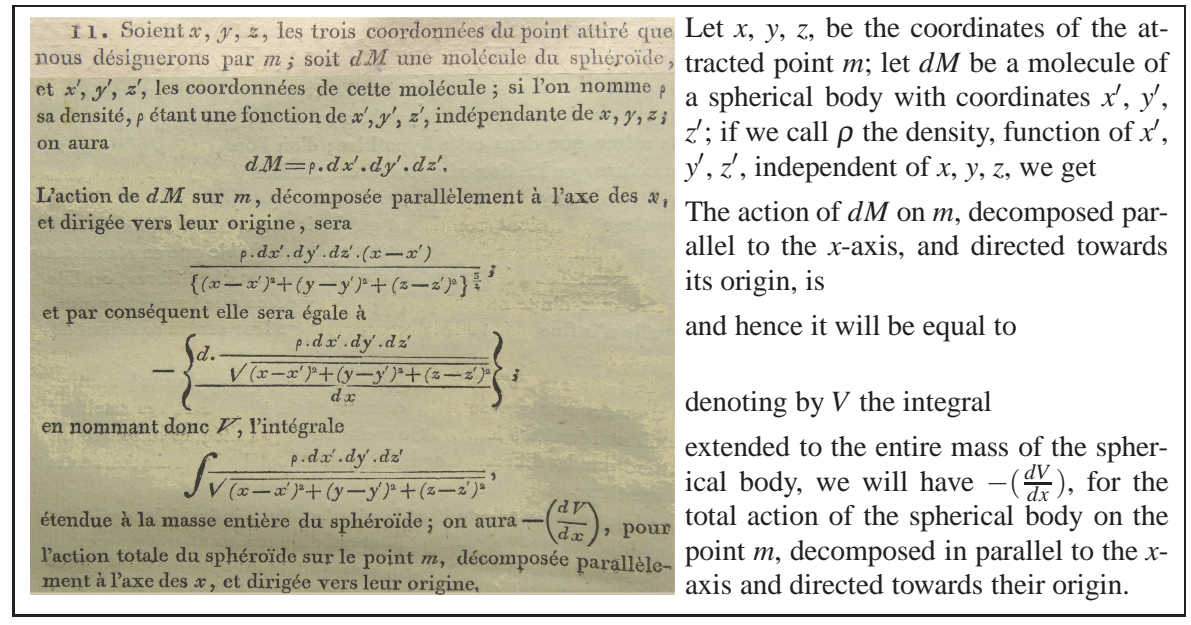

Fig. 2 Generalization of Laplace of the inverse square law of Newton to the case of a spherical body, arguing with molecules. Copied from the 1799 publication of Laplace's Mécanique Céleste [9, page 136]. 


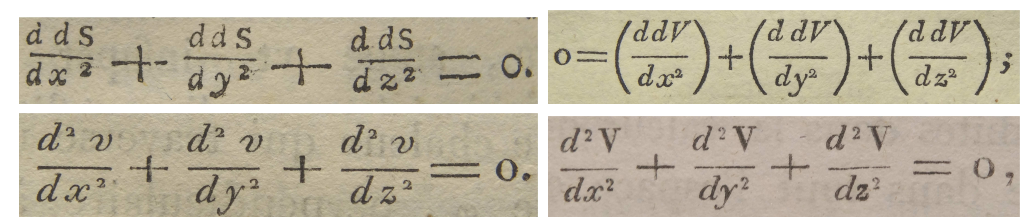

Fig. 3 Laplace equation by Euler in 1752 (top left), by Laplace in 1799 (top right), by Fourier in 1822 (bottom left), and by Kelvin in 1847 (bottom right)

Taking a derivative with respect $x$, and using $\frac{\partial}{\partial x} \frac{1}{r}=-\frac{x-\xi}{r^{3}}$, we obtain by comparing with (1), after a similar computation for $y$ and $z$,

$$
\mathbf{f}=-\left(\frac{\partial u}{\partial x}, \frac{\partial u}{\partial y}, \frac{\partial u}{\partial z}\right)
$$

Differentiating once more, we obtain $\frac{\partial}{\partial x} \frac{x-\xi}{r^{3}}=\frac{r^{3}-3(x-\xi)^{2} r}{r^{6}}$, and therefore, performing the same steps for $y$ and $z$ as well, that the potential function satisfies

$$
\Delta u=\frac{\partial^{2} u}{\partial x^{2}}+\frac{\partial^{2} u}{\partial y^{2}}+\frac{\partial^{2} u}{\partial z^{2}}=0, \quad \text { Laplace's equation! }
$$

This equation appeared already in Euler's Principia motus fluidorum [2] (E258, written 1752, published 1756) see Figure 3, but Euler could not really use it. It appeared again in the theory of heat transfer, published by Fourier [3] in 1822, see Figure 3. Fourier also argued with molecules, and Newton's law of cooling, in order to derive the equation.

Laplace's equation turned out to be absolutely fundamental, it appeared again in the theory of magnetism proposed by Gauss and Weber in Göttingen in 1839, in the theory of electric fields put forward by W. Thomson (the later Lord Kelvin, published in the Liouville Journal from 1847 on pages 256 and 496), in conformal maps (Gauss 1825), in the irrotational motion of fluids in two dimensions (Helmholtz 1858), and finally in complex analysis, in particular in Riemann's PhD Thesis in 1851 , which is available in a modern typeset version in [17].

\section{The Riemann Mapping Theorem}

Riemann was a prodigy already in high-school, and his mathematical talent impressed everybody:

"Ein Lehrer, der Rektor Schmalfuss, lieh ihm Legendres Zahlentheorie (Théorie des Nombres), ein schwieriges Werk von 859 Quartformat-Seiten, bekam sie aber schon eine Woche 


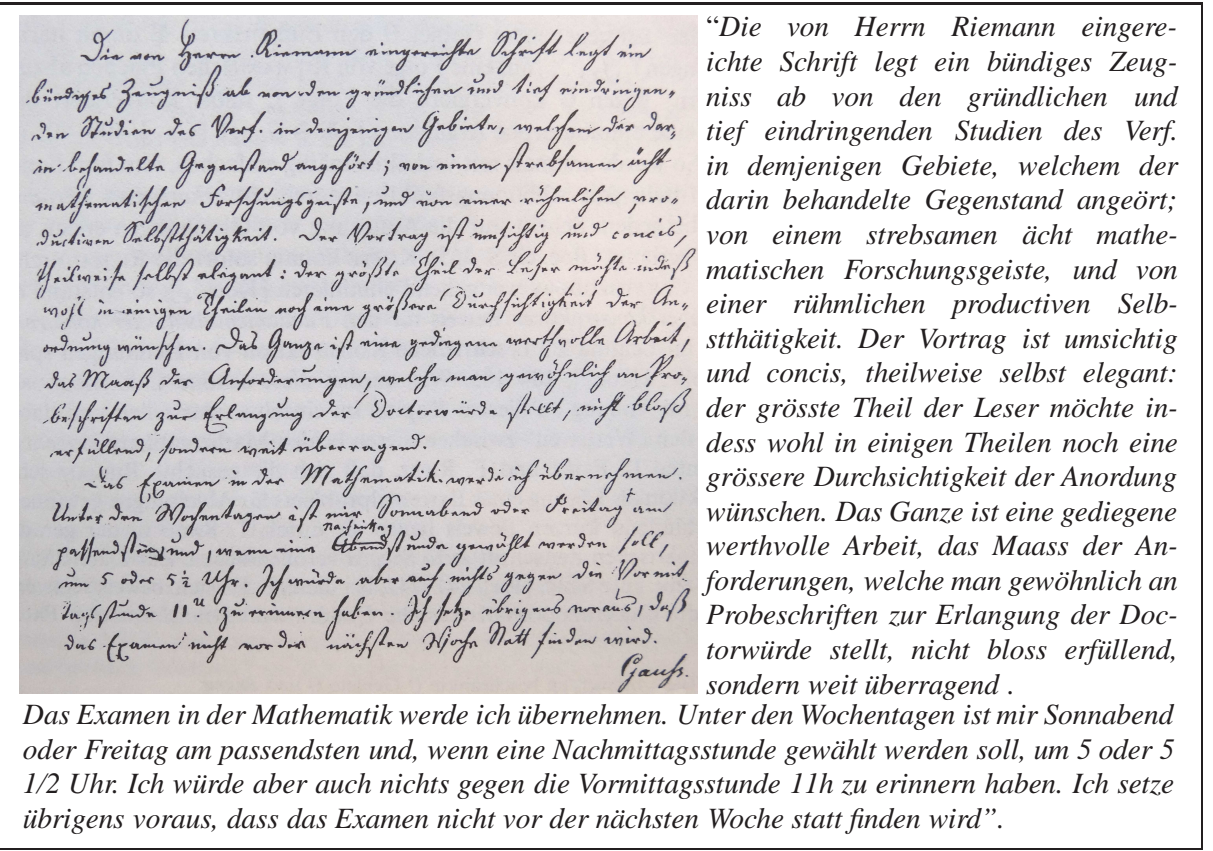

Fig. 4 Handwritten Laudatio of Gauss on Riemann's PhD thesis, copied from Remmert [16]

später zurück und fand, als er Riemann im Abitur über dieses Werk weit über das Übliche hinaus prüfte, dass Riemann sich dieses Buch vollständig zu eigen gemacht hatte." 2

Riemann's PhD supervisor was Gauss, who rarely praised the work of other mathematicians. We show the laudatio on Riemann's thesis in the original handwriting of Gauss in Figure $4^{3}$. Riemann build in his thesis the foundation of analytic function theory, and gave toward the end an example, which became the famous Riemann Mapping theorem:

\footnotetext{
2 "A teacher, Professor Schmalfuss, lend him Legendre's book on number theory, a very difficult work of 859 pages in quarto format, and he got it back already after a week. When he tested Riemann in his final high-school exam on this subject much more thoroughly than usual, he realized that Riemann had completely mastered the content of the book."

${ }^{3}$ The manuscript submitted by Riemann is a testament of the thorough and deep studies by the author in the area to which the treated subject belongs; of an aspiring and truly mathematical research spirit, and of a glorious, productive self-activity. The presentation is comprehensive and concise, partly even elegant: the major part of the readers would however in some parts still wish for more transparency and better arrangement. As a whole, it is a dignified valuable work, which does not only satisfy the requirement one usually imposes on a manuscript to obtain a $\mathrm{PhD}$ degree, but goes very far beyond.

The mathematics exam I will do myself. I prefer Sunday or Friday, and in the afternoon at 5 or 5:30 pm. I would also be available in the morning at $11 \mathrm{am}$. I assume that the exam will not be before next week.
} 
"Zwei gegebene einfach zusammenhängende Flächen können stets so aufeinander bezogen werden, dass jedem Punkte der einen ein mit ihm stetig fortrückender Punkt entspricht...;"4

Riemann also gave a constructive proof of this theorem. In modern notation, we need to find an analytic function $f$ which maps $\Omega$ to the unit disk and one point $z_{0} \in \Omega$ into 0 . We thus set $f(z):=\left(z-z_{0}\right) e^{g(z)}, g=u+i v$ an analytic function to be determined, in order to ensure that $z_{0}$ is the only point mapped into zero. In order to arrive from the boundary $\partial \Omega$ on the boundary of the disk with the mapping, we must have for all $z \in \partial \Omega$ that $|f(z)|=1$, which implies that

$$
1=|f(z)|=\left|\left(z-z_{0}\right) e^{u+i v}\right|=\left|\left(z-z_{0}\right)\right| e^{u} \Longrightarrow u(z)=-\log \left|z-z_{0}\right|, \forall z \in \partial \Omega .
$$

Since $g$ is analytic, the real part $u$ of $g$ satisfies Laplace's equation $\Delta u=0$ on $\Omega$, with boundary values given in (5). It thus suffices to solve for $u$, construct $v$ using the Cauchy-Riemann equations, and then the construction of $f$ is complete.

Riemann's PhD thesis was very well received by the mathematical world of that time, and widely studied. Among the first readers were also Weierstrass and Helmholtz:

"Weierstrass hatte die Riemannsche Dissertation zum Ferienstudium mitgenommen und klagte, dass ihm, dem Funktionentheoretiker, die Riemannschen Methoden schwer verständlich seien. Helmholtz bat sich die Schrift aus und sagte beim nächsten Zusammentreffen, ihm schienen die Riemannschen Gedankengänge völlig naturgemäss und selbstverständlich zu sein." (Funktionentheorie 1 von Reinhold Remmert, Georg Schumacher) ${ }^{5}$

Nevertheless, an important question remained: Riemann had used that a $u$ satisfying Laplace's equation on an arbitrary domain with given boundary conditions exists. But was this really true? When Riemann was challenged with this, he replied

"Hierzu kann in vielen Fällen ... ein Princip dienen, welches Dirichlet zur Lösung dieser Aufgabe für eine der Laplace'schen Differentialgleichung genügende Function ... in seinen Vorlesungen ... seit einer Reihe von Jahren zu geben pflegt." (Riemann 1857, Werke p. 97) ${ }^{6}$

The idea, which became known under the name of "Dirichlet principle", is to choose among all the functions defined on a given domain $\Omega$ with the prescribed boundary values the one that minimizes the integral

$$
J(u)=\iint_{\Omega} \frac{1}{2}\left(u_{x}^{2}+u_{y}^{2}\right) d x d y \quad \text { which is always non-negative. }
$$

But is the Dirichlet principle correct for an arbitrary, non-negative functional? Weierstrass gave in (1869, Werke 2, p. 49) a counter example: for the non-negative

\footnotetext{
4 Two simply connected surfaces can always be mapped one to the other, such that each point on the former moves continuously with the point on the latter...

5 Weierstrass had taken Riemann's $\mathrm{PhD}$ thesis as vacation reading, and complained that for a function theorist like him, the methods of Riemann were hard to understand. Helmholtz then also borrowed the thesis, and said on their next meeting, that for him, Riemann's thoughts seemed to be completely natural and self-evident.

6 To this end, one can often invoke a principle for finding a function that solves Laplace's equation, which Dirichlet has been using in his lectures over the past few years.
} 
functional

$$
\int_{-1}^{1}\left(x \cdot y^{\prime}\right)^{2} d x \rightarrow \min \quad y(-1)=a, y(1)=b
$$

the function $y(x)$ must have a small derivative when $x$ is large, to make the functional small. Hence the derivative can only be large when $x$ is close to zero, and the minimum is achieved for the step function, which is not differentiable at $x=0$. Weierstrass concludes

"Die Dirichlet'sche Schlussweise führt also in dem betrachteten Falle offenbar zu einem falschen Resultat."7

But Riemann only answered “... meine Existenztheoreme sind trotzdem richtig”, and Helmholtz commented "Für uns Physiker bleibt das Dirichletsche Prinzip ein Beweis"9.

\section{The Schwarz Alternating Method}

The entire mathematical world stood now in front of a big challenge, namely to show rigorously that for an arbitrary domain $\Omega$, Laplace's equation $\Delta u=0$ with prescribed boundary conditions $u=g$ on $\partial \Omega$ has a unique solution. For special domains, the answer had been known for quite some time: Poisson (1815) had found the solution formula for circular domains, and Fourier (1807) for rectangular domains using Fourier series. But the existence of solutions of Laplace's equation on arbitrary domains appeared hopeless !

It is at this moment, where Schwarz invented the first ever domain decomposition method [18]. His paper starts with the paragraph

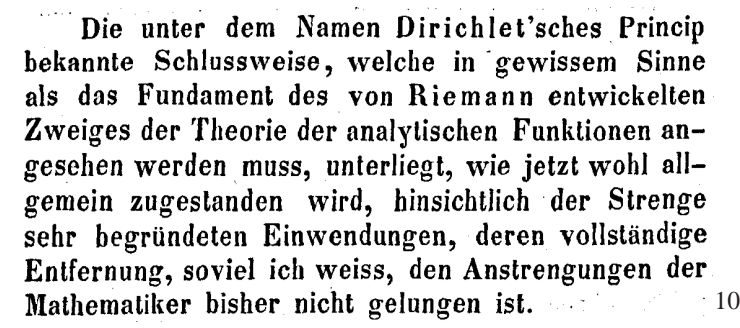

Schwarz then invents the famous alternating Schwarz method to prove existence and uniqueness of the solution of Laplace's equation on a domain composed of a disk and a rectangle, as shown from the original publication in Figure 5 on the left. His alternating method is given by

\footnotetext{
${ }^{7}$ Dirichlet's reasoning apparently leads to an incorrect result in this case [8].

8 ... my existence theorems nevertheless hold [8].

${ }^{9}$ For us physicists the Dirichlet principle remains a proof [8].

10 The method of conclusion, which became known under the name Dirichlet Principle, and which in a certain sense has to be considered to be the foundation of the theory of analytic functions de-
} 

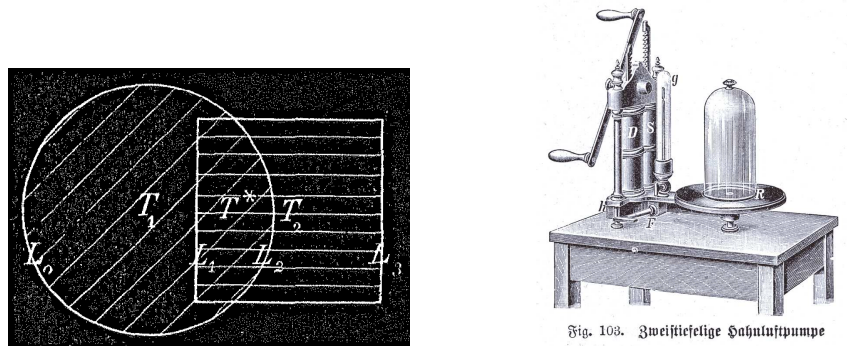

Fig. 5 Original drawing of Schwarz from 1870 on the left to explain his alternating method, and his physical interpretation of the method using a two level vacuum pump on the right

$$
\begin{aligned}
& \Delta u_{1}^{n}=0 \quad \text { in } T_{1}, \quad \Delta u_{2}^{n}=0 \quad \text { in } T_{2}, \\
& u_{1}^{n}=g \quad \text { on } L_{0}, \quad u_{2}^{n}=g \quad \text { on } L_{3} \text {, } \\
& u_{1}^{n}=u_{2}^{n-1} \text { on } L_{2}, \quad u_{2}^{n}=u_{1}^{n} \text { on } L_{1} \text {. }
\end{aligned}
$$

Since the method only uses solutions of Laplace's equation on the disk and the rectangle, for which the proof of the Dirichlet principle did not pose any difficulties, the method is well defined. Schwarz then proved the convergence of his method to a limit that satisfies Laplaces equation as well in the composed domain. Adding other circles or rectangles Schwarz then proved recursively the Dirichlet principle for more and more complicated domains. This closed the gap in Riemann's proof.

Schwarz also gave an analogy of his alternating method with a physical device, as indicated on the right in Figure 5: a vacuum pump with two cylinders. In order to create a vacuum in the inner chamber, one has to alternatingly pump with the two cylinders, similar to the subdomain solves in the alternating method.

\section{The Schwarz method as a computational tool}

At the beginning of the 20th Century, Hilbert (see [6, 7]) finally managed, after a hard struggle, to establish a theory for direct methods of variational calculus, which later led to the Ritz-Galerkin method (see e.g. [5]). The Schwarz method thus lost completely its importance as a theoretical tool. Curiously, some other decades later, its importance for practical computations was discovered: in 1965, Miller states [14]:

"Schwarz's method presents some intriguing possibilities for numerical methods. Firstly, quite simple explicit solutions by classical methods are often known for simple regions such as rectangles or circles. Also, better numerical solutions, from the standpoint of the computational work involved, are often known for certain types of regions than for others. By Schwarz's method, we may be able to extend these classical results and these computational advantages to more complicated regions."

veloped by Riemann, is subject to, like it is generally admitted now, very well justified objections, whose complete removal has eluded all efforts of mathematicians to the best of my knowledge. 
Fundamental early contributions to the theory were by Sobolev [19], who gave a variational convergence proof for the case of elasticity, Mikhlin [13], with a variational proof for convergence for general elliptic operators, and then the sequence of publications by Lions $[10,11,12]$. The complete breakthrough as a computational method came with the introduction of the two level additive Schwarz method [1].

\section{References}

1. Maksymilian Dryja and Olof B. Widlund. An additive variant of the Schwarz alternating method for the case of many subregions. Technical Report 339, also Ultracomputer Note 131, Department of Computer Science, Courant Institute, 1987.

2. Leonard Euler. Principia motus fluidorum. Novi Commentarii academiae scientiarum Petropolitanae, 6:271-311, 1756.

3. Joseph Fourier. Théorie analytique de la chaleur. Firmin Didot, père et fils, 1822.

4. Martin J. Gander. Schwarz methods over the course of time. ETNA, 31:228-255, 2008.

5. Martin J. Gander and Gerhard Wanner. From Euler, Ritz, Galerkin to modern computing. SIAM Rev., 54(4), 2012.

6. David Hilbert. Über das Dirichletsche Prinzip. Jahresbericht der Deutschen MathematikerVereinigung, 8:184-188, 1900. Reprinted in 'Journal für die reine und angewandte Mathematik' Vol 129, 1905, pp. 63-67.

7. David Hilbert. Über das Dirichletsche Prinzip. Mathematische Annalen, 59:161-186, 1904.

8. Felix Klein. Vorlesungen über die Entwicklung der Mathematik im 19. Jahrhundert. Berlin, 1926. Reprinted New York 1950 and 1967.

9. Pierre Simon Laplace. Traité de Mécanique Céleste. De l'Imprimerie de Crapelet, Paris (an VII), 1799.

10. Pierre-Louis Lions. On the Schwarz alternating method. I. In Roland Glowinski, Gene H. Golub, Gérard A. Meurant, and Jacques Périaux, editors, First International Symposium on Domain Decomposition Methods for Partial Differential Equations, pages 1-42, Philadelphia, PA, 1988. SIAM.

11. Pierre-Louis Lions. On the Schwarz alternating method II: Stochastic interpretation and orders properties. In Tony Chan, Roland Glowinski, Jacques Périaux, and Olof Widlund, editors, Domain Decomposition Methods, pages 47-70, Philadelphia, PA, 1989. SIAM.

12. Pierre-Louis Lions. On the Schwarz alternating method III: A variant for nonoverlapping subdomains. In Tony F. Chan, Roland Glowinski, Jacques Périaux, and Olof Widlund, editors, Third International Symposium on Domain Decomposition Methods for Partial Differential Equations, held in Houston, Texas, March 20-22, 1989, pages 202-223, Philadelphia, PA, 1990. SIAM.

13. S.G. Mikhlin. On the Schwarz algorithm. Doklady Akademii Nauk SSSR, 77:569-571, 1951.

14. Keith Miller. Numerical analogs to the Schwarz alternating procedure. Numer. Math., 7:91103, 1965.

15. Isaac Newton. Philosophiae Naturalis Principia Mathematica. Juffu Societatis Regiae ac Typis Josephi Streater, Londini, 1687.

16. R. Remmert. Funktionentheorie. Springer, 1991.

17. Berhard Riemann. Grundlagen für eine allgemeine Theorie der Functionen einer veränderlichen complexen Grösse. PhD thesis, Göttingen, 1851. Werke p. 3-34, transcribed by D. R. Wilkins, April 2000.

18. H. A. Schwarz. Über einen Grenzübergang durch alternierendes Verfahren. Vierteljahrsschrift der Naturforschenden Gesellschaft in Zürich, 15:272-286, Mai 1870.

19. S. L. Sobolev. L'Algorithme de Schwarz dans la Théorie de l'Elasticité. Comptes Rendus (Doklady) de l'Académie des Sciences de l'URSS, IV((XIII) 6):243-246, 1936.

20. Gerhard Wanner. Kepler, Newton and numerical analysis. Acta Numerica, 19:561-598, 2010. 